\title{
Controlled-release Formulations of Trifluralin Herbicide by Interfacial Polymerization as a Tool for Environmental
}

\section{Hazards}

\author{
Golamreza Daneshvari ${ }^{1}$, Ali Reza Yousefi 1,*, Mehdi Mohammadi ${ }^{2}$, Soodabeh Banibairami ${ }^{3}$, Parvin \\ Shariati $^{2}$, Abbas Rahdar ${ }^{4}$, George Z. Kyzas 5,*(D) \\ 1 Department of Plant Production \& Genetics, University of Zanjan, P.O. BOX. 4537138791, Zanjan, Iran; \\ rezadaneshvari@yahoo.com (G.D.); ayousefi@znu.ac.ir (A.R.-Y.); \\ 2 Bioprocess Engineering Department, National Institute of Genetic Engineering and Biotechnology (NIGEB), Tehran, Iran; \\ m.mohammadi@nigeb.ac.ir (M.M.); Shariati@nigeb.ac.ir (P.S.); \\ 3 Department of Chemistry, Agricultural Crops Applied Research Center, Karaj, Iran; banibairami@ yahoo.com (S.B.); \\ 4 Department of Physics, University of Zabol, Zabol 98613-35856, Iran; a.rahdar@uoz.ac.ir (A.R.); \\ 5 Department of Chemistry, International Hellenic University, Kavala, GR-654 04, Greece; kyzas@chem.ihu.gr (G.Z.K.); \\ * Correspondence: kyzas@chem.ihu.gr (G.Z.K.); ayousefi@znu.ac.ir (A.R.-Y.);
}

Scopus Author ID 17345938100 (G.Z.K.)

Received: 25.01.2021; Revised: 20.02.2021; Accepted: 23.02.2021; Published: 1.03.2021

\begin{abstract}
Trifluralin is a widely used herbicide that can be an environmental hazard due to its sensitivity to photodegradation and volatilization to the atmosphere. Using modern techniques, such as microencapsulation, may help maintain trifluralin activity for an appropriate period and reduce applications' quantity and frequency. This work aimed to develop controlled-release formulations of trifluralin by microencapsulation of the active ingredient using interfacial polymerization. The successful encapsulation of trifluralin in the polyurethane network was confirmed by IR and ${ }^{1} \mathrm{HNMR}$ spectroscopy, showing the two compounds' corresponding signals. Dissipation of trifluralin in the microencapsulation and EC formulations were tested with the herbicide exposure to UV light in a reactor for $0,2,4,6$, and $8 \mathrm{~h}$. The results showed that the formulation significantly affected herbicide dissipation $(\mathrm{P} \leq 0.01)$. With increasing $\mathrm{UV}$ exposure, the active ingredient in the $\mathrm{EC}$ formulation decreased linearly and reached $43 \%$ after $8 \mathrm{~h}$. In comparison, only $0.9 \%$ of the initial herbicide level in the microencapsulation was lost during the same time. Our results indicated that an effective herbicide such as trifluralin can be protected from volatilization and photodegradation by developing a microencapsulation formulation.
\end{abstract}

Keywords: controlled-release; environmental hazard; herbicides; UV light.

(C) 2021 by the authors. This article is an open-access article distributed under the terms and conditions of the Creative Commons Attribution (CC BY) license (https://creativecommons.org/licenses/by/4.0/).

\section{Introduction}

Weed infestation is one of the main limitations to crop production in agricultural systems. Several methods such as manual, mechanical, biological, and chemical control have been proposed to reduce weeds' negative effects on crop plant yield [1]. Among them, chemical control is the most applicable and cost-effective method for horticultural and agricultural crops. Trifluralin ( $\alpha, \alpha, \alpha$-trifluoro-2,6-dinitro- $N, N$-p-toluidine) is one of the most commonly used selective pre-planting herbicides in the dinitroaniline chemical family [2]. It has been registered for use in controlling annual grasses and broad-leaf weeds in important crops such as chickpea 
(Cicer ariealtinum L.), fennel (Foeniculum vulgare Mill.), common bean (Phaseolus vulgaris L.), lentil (Lens culinaris Medik), canola (Brassica napus L.), sunflower (Helianthus annuus L.), tomato (Lycopersicon esculentum L.) and some tropical ornamentals around the world [38].

Despite the widespread adoption of trifluralin in agriculture, the recommendation of this product has faced certain constraints. The main drawback is its specific chemical properties, which cause trifluralin to be lost rapidly through photodegradation (the breakdown of a substance by sunlight). Ultraviolet light (UV) is a more effective spectrum in changing herbicides' molecular structure through their chemical bonds' breakdown. All herbicides are susceptible to photodegradation, but for some, the effect is much more significant than for others. For example, trifluralin is yellow in color and has a peak light absorption at $376 \mathrm{~nm}$, very close to the UV peak $(400 \mathrm{~nm})$. Therefore, it is highly susceptible to photodegradation [9]. The second limitation is the susceptibility of this product to losses by volatilization under warm temperatures. According to Maas et al. [10], under laboratory conditions, $50 \%$ of the applied amount of trifluralin was lost by volatilization only one day after spraying. It completely degraded in 7 days at $76^{\circ} \mathrm{F}$ in non-autoclaved soils, whereas only $20 \%$ had degraded at $38^{\circ} \mathrm{F}[11]$.

Both photodegradation and volatilization can reduce the biological activity of this herbicide [12]. Due to the poor control of target weeds, the use of complementary weed control measures or increasing the quantity and frequency of application should maintain crop yield. Repetitive spraying, in addition to the costs, increases the release of herbicides into the environment. Moreover, sensitive non-target plants which grow away from the treated fields may also be adversely affected by volatilization [13]. To alleviate the negative effects of photodegradation and volatilization on trifluralin efficacy, growers have been advised to incorporate the herbicide into the soil at a depth of 1 to 2 inches, using a rotary hoe disc, grounddriven rolling cultivators, or harrow soon after application [11]. However, mixing herbicides into the soil needs additional energy and can increase soil compaction.

The other problem associated with this product is that, despite its low water solubility, it has been reported as a water contaminant [14]. To solve these potential problems [15], applying controlled-release formulations of the herbicide could be cost-effective and an environmentally-friendly method [16].

Although more investigations have been carried out in the preparation of polyurea microcapsules using conventional chemical agents, less attention has been paid to active agents' encapsulation using promoters or catalysts to control shell microstructure and morphology. In the present research, the effects of the nature of emulsifier, shell monomer composition, and the PPINO promoter on the morphology, microstructure, and thermal properties of microcapsules containing trifluralin were investigated.

Depending on the type of polymeric material, the properties of the microcapsule may change extensively. Ethylcellulose [17], liposomes [18], and lignin [19] are biodegradable polymers that are generally used as safe carriers for herbicides. Numerous investigations on polyurethane use in biomedical applications have been reported because of its excellent physical and mechanical properties and high biocompatibility [20]. Entrapment of drugs and pesticides and microencapsulation of water-soluble reagents in a polyurethane network have also been reported in several studies [21-22]. Shukla et al. [23] have reported 
microencapsulation of the water-soluble pesticide, monocrotophos (MCR), using polyurethane as the carrier polymer for the first time [23]. The delivery of theophylline from microspheres of commercially available polyurethane has also been reported [24]. However, to the best of our knowledge, there is no report on trifluralin's microencapsulation in a polyurethane network.

With help to protect trifluralin from photodegradation or volatilization, the use of a reduced herbicide rate can be recommended. Reduction of environmental risk associated with herbicide applications and simplicity of handling are additional advantages of this formulation. Furthermore, modern techniques such as microencapsulation may help maintain the activity of trifluralin for an appropriate period. Therefore, this work aimed to create controlled-release formulations of trifluralin by microencapsulation of the active ingredient using interfacial polymerization and test its capacity to reduce herbicide sensitivity to photodegradation and volatilization.

\section{Materials and Methods}

Analytical grade trifluralin (95\% purity) (Nanjing Fengshan Chemical Co., Ltd, China) was used for designing controlled-release formulations. Ethylenediamine,4,4'-methylene diphenyl diisocyanate, Arabic gum, and xylene were obtained from Merck Co., Germany. Fourier transform infrared spectra (FT-IR) were recorded on a Bomen FT-IR-MB-series instrument by using the $\mathrm{KBr}$ pellet technique. ${ }^{1} \mathrm{H}$ NMR spectrum was recorded on a Bruker $250 \mathrm{MHz}$ spectrometer. The chemical shifts are expressed in ppm.

\subsection{Preparation of aqueous and organic phases.}

To prepare an aqueous phase system at room temperature, $2.2 \mathrm{~g}$ of Arabic gum as a surface activator and stabilization of active ingredient [25-27] was dissolved in $33.5 \mathrm{~mL}$ of water. To prepare the organic phase, $21 \mathrm{~g}$ of a herbicide-active ingredient was dissolved in 50 $\mathrm{g}$ of xylene as the solvent. Then $0.2 \mathrm{~g}$ of 4,4'-methylene diphenyl diisocyanate was added to the xylene solution. The aqueous phase was then homogenized at $4000 \mathrm{rpm} / \mathrm{min}$, to which the organic phase was then added until small drops from the organic layer appeared in the aqueous phase.

\subsection{Addition of a second additive to the organic layer and interface polymerization.}

After preparing the homogenous phase, $6 \mathrm{~g}$ of ethylenediamine (5\%) was added to the system until polymeric covers were formed and the polymerization reaction was completed. To prevent deposition of capsules, an antibacterial agent (at a concentration of $0.1 \%$ ), and 37.9 $\mathrm{g}$ of the stabilizer were added to the system and the solution was mixed at $200 \mathrm{rpm} / \mathrm{min}$ for 30 $\min$.

\subsection{Quality and quantity controls.}

\subsubsection{GC analysis.}

The quantity of active ingredients in each sample was quantified using a GC instrument (Agilent technology7890A) equipped with HP5, 30m $\times 0.320 \mathrm{~mm} \times 0.25$ microns, and a flame ionization detector (FID). Nitrogen was used as a carrier gas at a constant flow of $2.5 \mathrm{~mL} / \mathrm{min}$. 
The column temperature was kept at $200{ }^{\circ} \mathrm{C}$. The injector and detector temperatures were set at $220^{\circ} \mathrm{C}$ and $250{ }^{\circ} \mathrm{C}$, respectively.

\subsubsection{Active ingredient determination.}

THF was used for the extraction of trifluralin from the capsules. For the sample solutions preparation, $1 \pm 0.1 \mathrm{~g}$ of each sample was weighed in a $50 \mathrm{~mL}$ volumetric flask, to which $25 \mathrm{~mL}$ of THF was then added. The solution was mixed in an ultrasonic $40-50{ }^{\circ} \mathrm{C}$ for 15 min and was then shaken for another10 min.

\subsubsection{Preparation of standard solution.}

$0.2 \mathrm{~g}$ sample of trifluralin was weighed in a $50 \mathrm{~mL}$ volumetric flask, to which $25 \mathrm{~mL}$ of THF was then added. The solution was mixed in an ultrasonic. Both the standard and sample solutions were injected into the GC.

\subsubsection{Free trifluralin determination.}

For the determination of non-encapsulated trifluralin, $2 \pm 0.1 \mathrm{mg}$ of the formulation was weighed in an Erlenmeyer flask, and $50 \mathrm{~mL}$ of water was then added and mixed. After that, 25 $\mathrm{mL}$ of $\mathrm{n}$-hexane was added to the solution, which was shaken slowly for $10 \mathrm{~min}$ to dissolve the free trifluralin. The organic layer was then separated by a decanter funnel and injected into the GC. Physical and chemical properties, such aspH, suspensibility, wet sieve, persistent foam, and heat storage tests, were determined.

\subsection{Dissipation of trifluralin with exposure to natural sunlight or UV light.}

The encapsulated trifluralin's photodegradation was evaluated with exposure of the herbicide to natural sunlight for $0,8,16,24,32$, and $40 \mathrm{~h}$. The experiment was arranged as a factorial, complete randomized design with three replications per treatment. The formulation type and duration of herbicide exposure to sunlight were considered a first and second factor. At the above-mentioned exposure times, samples were taken for formulation experiments and also stored for subsequent GC analysis.

To evaluate the microencapsulation formulation's photodegradation relative to that of the EC formulation, the herbicide was exposed to UV light in a reactor for $0,2,4,6$, and $8 \mathrm{~h}$. The experiment was arranged as a factorial, complete randomized design with four replications per treatment. The formulation type and duration of herbicide exposure to sunlight were considered a first and second factor. Samples were taken at the times mentioned above for formulation experiments and were also stored for subsequent GC analysis.

Dissipationdata were analyzed using ANOVA with the PROC GLM procedure in the SAS software version 9.1 (SAS Institute, 2002). Before analyzing the data, the assumption of a homogeneous variation was tested. 


\section{Results and discussion}

\subsection{Physical and chemical properties.}

Microencapsulation of trifluralin in a polyurethane network was performed by in situ interfacial polymerization of 4,4'-methylene diphenyl diisocyanate in the presence of trifluralin and ethylenediamine as a chain extending agent (Figure 1). In general, two main processes can be used to prepare microcapsules from the polycondensation of polyurethane. In normal microencapsulation, polymerization of 4,4'-methylene diphenyl diisocyanate with a chain extending agent occurs in a single phase with a fast reaction rate. On the other hand, in interfacial polymerization, the monomer and chain extending agent are separately present in a two-immiscible phase system. Some of the advantages of microcapsules produced by interfacial polymerization include acquiring elevated mechanical and chemical properties, high active loading capacities, and adaptable delivery systems. In this study, the process of interfacial polymerization produced microcapsules with a mean diameter of 5 to $15 \mu \mathrm{m}$, which is in good agreement with the previously reported size for monocrotophos' microencapsulation in polyurethane [23,28-30]. Ozkan et al. [31] reported that release characteristics of microcapsules could affect by the particle size.

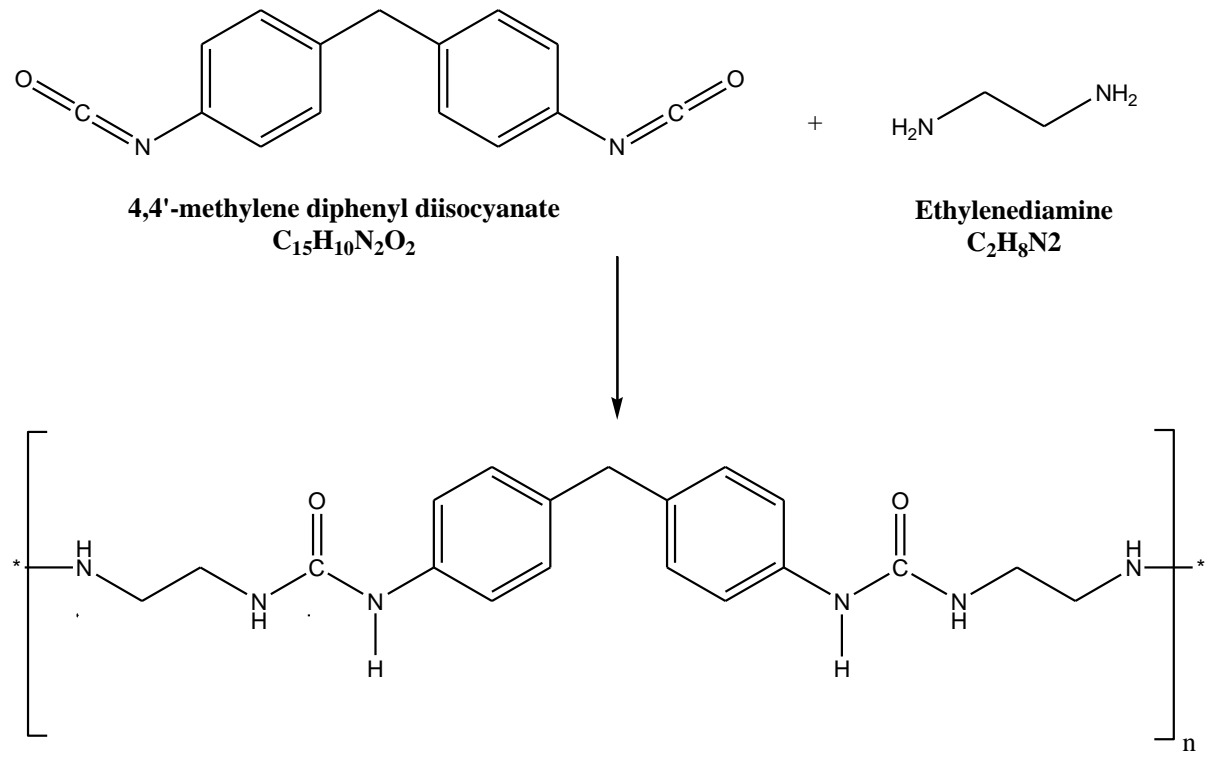

Figure 1. Polyurethane preparation via interfacial polymerization.

Different tests were used to evaluate the pesticide-loaded polyurethane's physical and chemical properties (Table 1). The results show the loading of $98.5 \%$ for trifluralin in the polymer network under the conditions mentioned above.

Table 1. Physical and chemical properties of created microencapsulation formulation of trifluralin.

\begin{tabular}{l|c|c} 
& Before stability test & After stability test $^{\text {a }}$ \\
\hline Active ingredient $(\%)$ & 20.10 & 20.16 \\
\hline none-encapsulated $\left(\mathrm{g} \mathrm{kg}^{-1}\right.$ of formulation) & 15 & - \\
\hline Suspensibility (\%) & 87.0 & 85.4 \\
\hline $\mathrm{pH}$ & 6.9 & 6.7 \\
\hline Wet sieve test (\%) & 0.12 & 0.20 \\
\hline Persistent foam $(\mathrm{mL} /$ after 1 min) & 2 & - \\
\hline${ }^{a}$ storage at elevated temperature $\left(54{ }^{\circ}\right.$ C for 14 days) &
\end{tabular}


This large value for the encapsulated trifluralin exhibits the high loading capacity of polyurethane in capturing small pesticide molecules. The suspensibility test was also conducted to determine the percent suspensibility of dry pesticide formulations. The results show $87 \%$ suspensibility for the final product, which decreases to $85.4 \%$ after carrying out the heat stability test (Table 1). This negligible decrease in suspensibility confirms the high stability of the synthesized product's physical structure when exposed to high temperatures. The amount of foam that was formed after dilution with water in a spray tank during application of the microencapsulated trifluralin was found to be $2 \mathrm{~mL}$ (Table 1). Polyurethane formation during the course of reactions was checked in all samples by FT-IR spectroscopy. The most predominant peaks in the polyurethane infrared spectrum were for the carbonyl $(\mathrm{C}=\mathrm{O})$ and $\mathrm{N}-$ $\mathrm{H}$ stretching absorptions at 1734 and $3365 \mathrm{~cm}^{-1}$, respectively. Furthermore, the isocyanate (NCO) peak at around $2270 \mathrm{~cm}^{-1}$ was absent, indicating the absence of residual monomer in the polymer (Figure 2 ).

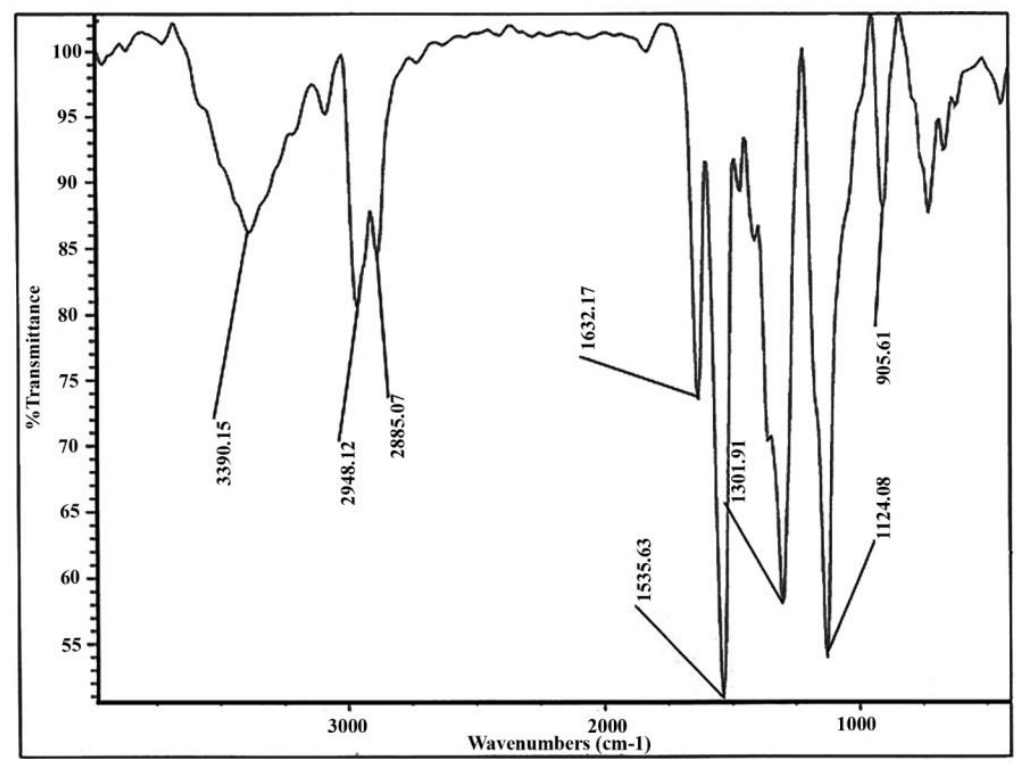

Figure 2. FT-IR spectrum of encapsulated trifluralin.

FT-IR spectroscopy was also used to investigate the chemical structure of the final product. Figure 2 displays the FT-IR spectrum of the drug-entrapped polymer. The successful encapsulation of trifluralin in a polyurethane network can be confirmed by the corresponding bands of both the drug and polymer backbone.

The band at $3390 \mathrm{~cm}^{-1}$ indicates the $\mathrm{N}-\mathrm{H}$ stretching mode. The bands at $2948 \mathrm{~cm}^{-1}$ and $2882 \mathrm{~cm}^{-1}$ are related to the stretching vibrations of the aliphatic $\mathrm{C}-\mathrm{H}$ bonds in both trifluralin and polyurethane. The bands around $1632 \mathrm{~cm}^{-1}$ can be attributed to the carbonyl group in the polymer backbone's stretching vibration. The intense $\mathrm{N}-\mathrm{O}$ stretching vibrations at $1535 \mathrm{~cm}^{-1}$ (asymmetrical) and $1301 \mathrm{~cm}^{-1}$ (symmetrical) together with the aromatic $\mathrm{C}-\mathrm{H}$ stretching band around $3100 \mathrm{~cm}^{-1}$ confirm the presence of trifluralin in the polymer backbone [22].

${ }^{1} \mathrm{H}-\mathrm{NMR}$ analysis of the trifluralin-loaded polymer was also performed to confirm the successful encapsulation process (Figure 3). The resulting spectrum for this compound is a combination of signals of both trifluralin and the polymer backbone, dominated by intense resonance signals at $8.46 \mathrm{ppm}$ (aromatic $\mathrm{C}-\mathrm{H}, 2 \mathrm{H}$, singlet), $2.9 \mathrm{ppm}\left(-\mathrm{CH}_{2}-\mathrm{N}, 4 \mathrm{H}\right.$, triplet), $1.47 \mathrm{ppm}\left(-\mathrm{CH}_{2}-, 4 \mathrm{H}\right.$, sextet) and $0.77 \mathrm{ppm}(-\mathrm{CH} 3,6 \mathrm{H}$, triplet) corresponding to the trifluralin 
protons (Figure 3). The most prominent proton chemical shifts in the polymer appeared at 6.9$7.2 \mathrm{ppm}$ as a multiplet, which belongs to the aromatic protons of 4,4'-methylene diphenyl diisocyanate in the polymer backbone, indicating that trifluralin molecules were successfully entrapped in the polyurethane chains.

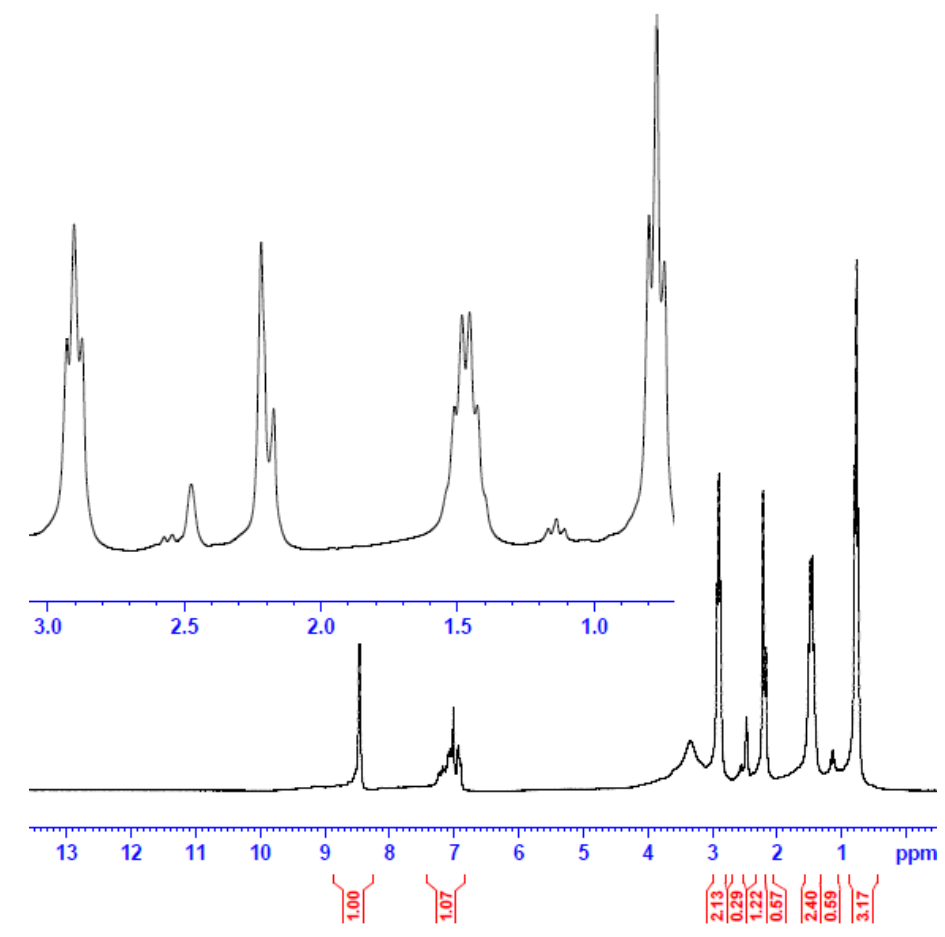

Figure 3. ${ }^{1} \mathrm{HNMR}$ spectrum of encapsulated trifluralin in DMSO- $\mathrm{d}_{6}$.

\subsection{Active ingredient dissipations with exposure to natural sunlight.}

Loss of trifluralin active ingredient was significantly affected by both formulation and the time of exposure to natural sunlight. The interaction effect was also significant (Table 2). Losingactive ingredients in the various formulations of trifluralin by exposure to sunlight is shown in Figure 4. Following $8 \mathrm{~h}$ of direct exposure of the EC formulation to natural sunlight, $2 \%$ of the active ingredient was dissipated, while after $40 \mathrm{~h}$ of exposure to sunlight, about $11 \%$ of the active ingredient was dissipated (Figure 4).

Unlike the EC formulation, the amount of active ingredient in the microencapsulation formulation was not significantly decreased following 8 and $16 \mathrm{~h}$ of exposure to natural sunlight. Exposure for up to $40 \mathrm{~h}$ resulted in only $6 \%$ loss of the active herbicide ingredient (Figure 4). Vasilakoglou and Eleftherohorinos (1997) reported that alachlor, as a microencapsulation formulation, was less volatile and protected from photodegradation.

Table 2. Analyses of variance of the effects of formulation, time of exposure to natural light, and their interaction on trifluralin dissipation

\begin{tabular}{l|l|l|l} 
Source of variation & Df & MS & P-value \\
\hline Formulation $(\mathrm{F})$ & 1 & 26.976 & $\leq 0.01$ \\
\hline Time of exposure (T) & 5 & 71.775 & $\leq 0.01$ \\
\hline F $\times \mathrm{T}$ & 5 & 5.482 & $\leq 0.01$ \\
\hline Error & 24 & 0.120 & -
\end{tabular}




\subsection{Active ingredient dissipations with exposure to UV light.}

Both formulation and the time of exposure to direct UV light were determinant factors in the loss of the trifluralin active ingredient (Table 3). The actual value of the remaining herbicide active ingredient in relation to the time of exposure to UV light is shown in Figure 5.

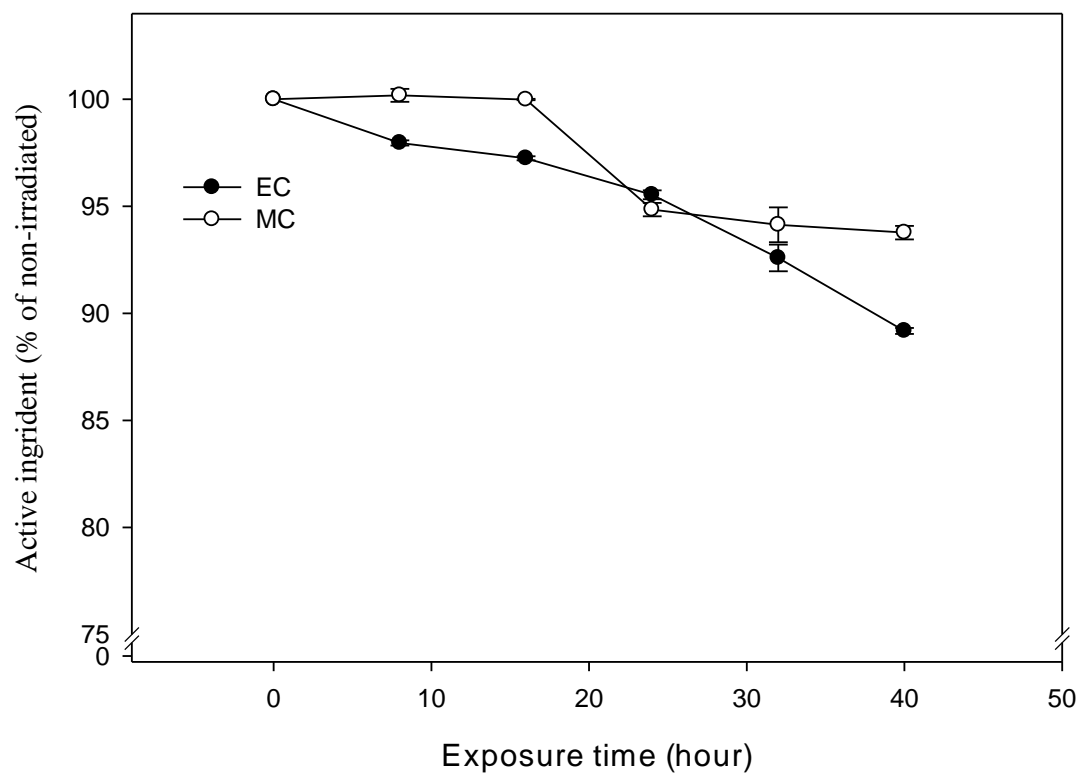

Figure 4. Loss of active ingredient of two formulations of trifluralin following exposure to natural sunlight. Vertical lines are the standard deviation of the mean.

Table 3. Analyses of variance of the effects of formulation, time of exposure to artificial UV light, and their interaction on Trifluralin dissipation

\begin{tabular}{l|l|l|l} 
Source of variation & Df & MS & P-value \\
\hline Formulation $(\mathrm{F})$ & 1 & $0 / 0117$ & $\leq 0.01$ \\
\hline Time of exposure $(\mathrm{T})$ & 4 & $0 / 00212$ & $\leq 0.01$ \\
\hline F $\times \mathrm{T}$ & 4 & $0 / 00166$ & $\leq 0.01$ \\
\hline Error & 30 & $0 / 000113$ & -
\end{tabular}

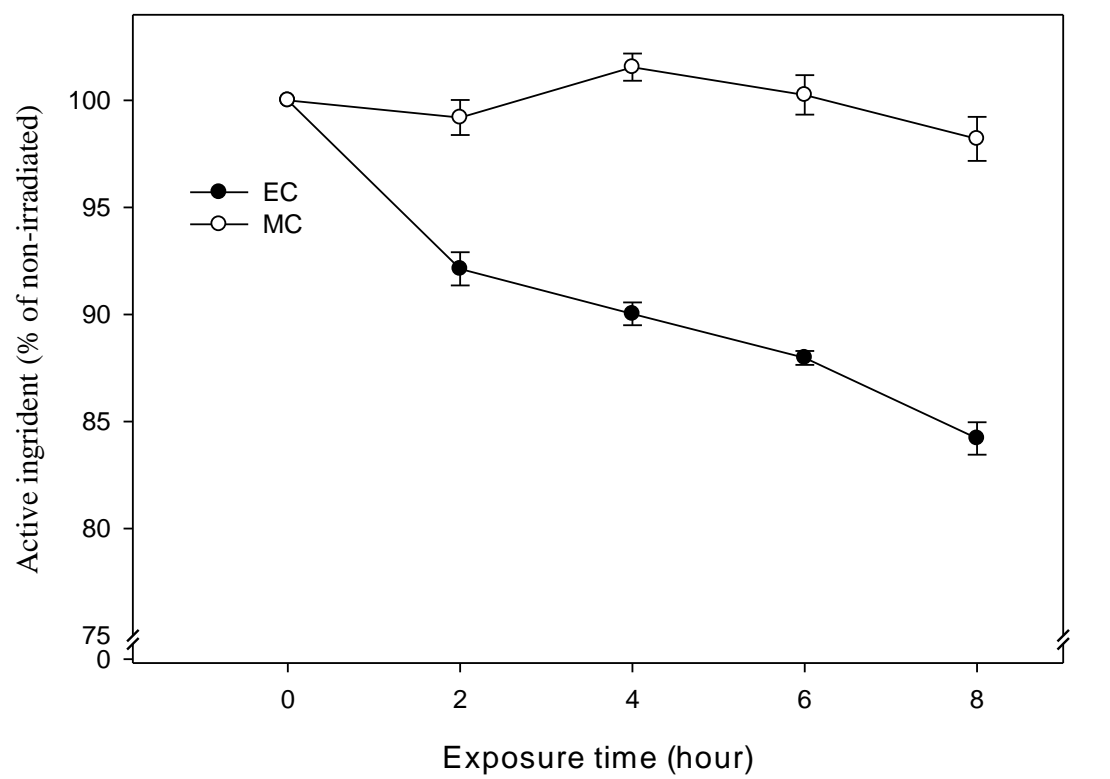

Figure 5. Loss of active ingredient of two formulations of trifluralin following exposure to UV light in a photochemical reactor. Vertical lines are the standard deviation of the mean. 
The results clearly showed that with increasing exposure time, the EC formulation's active ingredient decreased linearly $\left(y=-1.787 x+98.01, R^{2}=0.91\right)$. Following exposure to direct UV light for $8 \mathrm{~h}$, about $16 \%$ of the active ingredient was dissipated. However, the dissipation of the active ingredient was effectively decreased using the microencapsulated formulation. For example, during a $6 \mathrm{~h}$ exposure of the microencapsulated formulation to UV light, no significant losses in the active ingredient were detected and, exposure for up to $8 \mathrm{~h}$ resulted in only a $1.8 \%$ loss of the active herbicide ingredient (Figure 5). As mentioned before, $98.5 \%$ of the trifluralin was loaded onto the polymer network. In other words, $1.5 \%$ of the noneencapsulated trifluralin was present. It would appear that the UV light only affects the noneencapsulated fraction of trifluralin. Microencapsulation controls the active ingredients' release rate and protects susceptible materials from undesirable environmental conditions [32-36].

\section{Conclusions}

The use of herbicides is fundamental in maintaining crop yields and expanding the extent and production area [37-45]. Under field conditions, environmental factors such as light can have adverse effects on herbicide efficacy. Hence, growers are forced to use higher levels or repeat the spraying process. Microencapsulation is one of the most important industrial processes used for the production of controlled-release agricultural formulations. The main function of encapsulation is to protect the active ingredient from the undesirable effects of environmental factors and release it at an appropriate speed, reducing its levels in the environment because lower amounts or fewer applications are required. In this study, the microencapsulation of trifluralin by polyurethane using an in situ interfacial polymerization method was achieved. Assessment of particle size indicated a maximal size of $85 \mu \mathrm{m}$ for the obtained microcapsules. We confirmed the successful microencapsulation of trifluralin by using IR and ${ }^{1} \mathrm{HNMR}$ spectroscopy, both of which showed the corresponding signals of the polymer and trifluralin. This work also showed that an effective and economical herbicide such as trifluralin could be protected from volatilization and photodegradation by synthesizing microencapsulated formulations using interfacial polymerization. Accordingly, growers have sufficient time to incorporate the herbicide into the soil.

\section{Funding}

This research has no funding.

\section{Acknowledgments}

This research has no acknowledgment.

\section{Conflicts of Interest}

The authors declare no conflict of interest.

\section{References}

1. Nosratti, I.; Mobli, A.; Mohammadi, G.; Yousefi, A.R.; Sabeti, P.; Chauhan, B.S. The problem of Orobanche spp. and Phelipanche spp. and their management in Iran. Weed Sci. 2020, 68, 555-564, https://doi.org/10.1017/wsc.2020.61. 
2. Chen, J.; Goggin, D.; Han, H.; Busi, R.; Yu, Q.; Powles, S. Enhanced Trifluralin Metabolism Can Confer Resistance in Lolium rigidum. J. Agric. Food Chem. 2018, 66, 7589-7596, https://doi.org/10.1021/acs.jafc.8b02283.

3. Chaudhari, S.; Jennings, K.M.; Culpepper, S.; Batts, R.B.; Bellinder, R. Turnip Tolerance to Preplant Incorporated Trifluralin. Weed Technol. 2019, 33, 123-127, https://doi.org/10.1017/wet.2018.66.

4. Chowdhury, I.F.; Doran, G.S.; Stodart, B.J.; Chen, C.; Wu, H. Trifluralin and Atrazine Sensitivity to Selected Cereal and Legume Crops. Agronomy 2020, 10, https://doi.org/10.3390/agronomy10040587.

5. Nosratti, I.; Mahdavi-Rad, S.; Heidari, H.; Saeidi, M. Differential tolerance of pumpkin species to bentazon, metribuzin, trifluralin, and oxyfluorfen. Planta Daninha 2017, 35, 1-9, https://doi.org/10.1590/s010083582017350100066.

6. Karimmojeni, H.; Yousefi, A.R.; Kudsk, P.; Bazrafshan, A.H. Broadleaf Weed Control in Winter-Sown Lentil (Lens culinaris). Weed Technol. 2015, 29, 56-62, https://doi.org/10.1614/WT-D-13-00184.1.

7. Boyd, N.S.; Steed, S. Potted tropical ornamental tolerance to multiple PRE herbicides. Weed Technol. 2020, 1-5, https://doi.org/10.1017/wet.2020.133.

8. Adjesiwor, A.T.; Claypool, D.A.; Kniss, A.R. Dry bean response to preemergence flumioxazin. Weed Technol. 2020, 34, 197-201, https://doi.org/10.1017/wet.2019.87.

9. Cobb, A.H.; Reade, J.P.H. Herbicides and Plant Physiology. John Wiley \& Sons 2010, https://doi.org/10.1002/9781444327793.

10. Maas, G.; Pestemer, W.; Krasel, G. Indirekte Abdrift/Verflüchtigung von Herbiziden von Oberflächen. Z. Pflkrankh. Pflschutz., Sonderheft 1988, 11, 249-258.

11. Monaco, T.J.; Weller, S.C.; Ashton, F. M., Weed science: principles and practices. John Wiley \& Sons 2002.

12. Sopeña, F.; Maqueda, C.; Morillo, E. Controlled release formulations of herbicides based on microencapsulation. Ciencia e Investigacion Agraria 2009, 36, 27-42, http://dx.doi.org/10.4067/S071816202009000100002.

13. Breeze, V.G. Phytotoxicity of Herbicide Vapor. In Proceedings of Rev. Environ. Contam. Toxicol., New York, NY, 1993; 29-54.

14. Zimmerman, L.R.; Thurman, E.M.; Bastian, K.C. Detection of persistent organic pollutants in the Mississippi Delta using semipermeable membrane devices. Sci. Total Environ. 2000, 248, 169-179, https://doi.org/10.1016/S0048-9697(99)00540-9.

15. Ghitulica, S. S.; Vasile, O. R.; Trusca, R.; Neacsu, I. A.; Vasile, B. S. Porous ceramic support embedded with microorganisms used in water purification. Roman. J. Mater. 2019, 49, 33-41.

16. Heydari, M.; Yousefi, A.R.; Rahdar, A.; Nikfarjam, N.; Jamshidi, K.; Bilal, M.; Taboada, P. Microemulsions of tribenuron-methyl using Pluronic F127: Physico-chemical characterization and efficiency on wheat weed. J. Mol. Liq. 2021, 326, 115263, https://doi.org/10.1016/j.molliq.2020.115263.

17. Elbahri, Z.; Taverdet, J.L. Optimization of an herbicide release from ethylcellulose microspheres. Polym. Bull. 2005, 54, 353-363, https://doi.org/10.1007/s00289-005-0385-2.

18. Sánchez-Verdejo, T.; Undabeytia, T.; Nir, S.; Maqueda, C.; Morillo, E. Environmentally Friendly Slow Release Formulations of Alachlor Based on Clay-Phosphatidylcholine. Environ. Sci. Technol. 2008, 42, 5779-5784, https://doi.org/10.1021/es800743p.

19. Fernández-Pérez, M.; Villafranca-Sánchez, M.; Flores-Céspedes, F.; Pérez-García, S.; Daza-Fernández, I. Prevention of chloridazon and metribuzin pollution using lignin-based formulations. Environ. Pollut. 2010, 158, 1412-1419, https://doi.org/10.1016/j.envpol.2009.12.040.

20. Król, P.; Król, B. Structures, properties and applications of the polyurethane ionomers. J. Mater. Sci. 2020, 55, 73-87, https://doi.org/10.1007/s10853-019-03958-y.

21. Grigorieva, M.; Gladir, I.; Galatenko, N.J.J.o.B.; Polymers, C. The Polyurethane-Drug Composites: Synthesis, Properties and a Kinetic Model. 2001, 16, 307 - 314.

22. Marconi, W.; Francolini, I.; Piozzi, A.; Rosa, R.D. Antibiotic Releasing Urethane Polymers for Prevention of Catheter Related Infections. J. Bioact. Compatible Polym. 2001, 16, 393-407, https://doi.org/10.1106/G5EB-LL73-K59A-7YBF.

23. Shukla, P.G.; Kalidhass, B.; Shah, A.; Palaskar, D.V. Preparation and characterization of microcapsules of water-soluble pesticide monocrotophos using polyurethane as carrier material. J. Microencaps. 2002, 19, 293304, https://doi.org/10.1080/02652040110081343. 
24. Subhaga, C.S.; Ravi, K.G.; Sunny, M.C.; Jayakrishnan, A. Evaluation of an aliphatic polyurethane as a microsphere matrix for sustained theophylline delivery. J. Microencaps. 1995, 12, 617-625, https://doi.org/10.3109/02652049509006792.

25. Corrêa-Filho, L.C.; Lourenço, M.M.; Moldão-Martins, M.; Alves, V.D. Microencapsulation of $\beta$ - Carotene by Spray Drying: Effect of Wall Material Concentration and Drying Inlet Temperature. International Journal of Food Science 2019, 2019, 8914852, https://doi.org/10.1155/2019/8914852.

26. Corrêa-Filho, L.C.; Moldão-Martins, M.; Alves, V.D. Advances in the Application of Microcapsules as Carriers of Functional Compounds for Food Products. Applied Sciences 2019, 9, https://doi.org/10.3390/app9030571.

27. Šturm, L.; Osojnik Črnivec, I.G.; Istenič, K.; Ota, A.; Megušar, P.; Slukan, A.; Humar, M.; Levic, S.; Nedović, V.; Kopinč, R.; Deželak, M.; Pereyra Gonzales, A.; Poklar Ulrih, N. Encapsulation of non-dewaxed propolis by freeze-drying and spray-drying using gum Arabic, maltodextrin and inulin as coating materials. Food Bioprod. Process. 2019, 116, 196-211, https://doi.org/10.1016/j.fbp.2019.05.008.

28. Ma, Y.; Li, Z.; Wang, H.; Li, H. Synthesis and optimization of polyurethane microcapsules containing [BMIm]PF6 ionic liquid lubricant. J. Colloid Interface Sci. 2019, 534, 469-479, https://doi.org/10.1016/j.jcis.2018.09.059.

29. Li, D.; Wang, Y.; Wang, J.; Liu, H. Effect on the characterization of metolachlor polyurea microcapsules with urea instead of polyamines. Des Monomers Polym 2019, 22, 140-149, https://doi.org/10.1080/15685551.2019.1653031.

30. Song, Y.; Chen, K.-F.; Wang, J.-J.; Liu, Y.; Qi, T.; Li, G.L. Synthesis of Polyurethane/Poly(ureaformaldehyde) Double-shelled Microcapsules for Self-healing Anticorrosion Coatings. Chin. J. Polym. Sci. 2020, 38, 45-52, https://doi.org/10.1007/s10118-019-2317-x.

31. Ozkan, G.; Franco, P.; De Marco, I.; Xiao, J.; Capanoglu, E. A review of microencapsulation methods for food antioxidants: Principles, advantages, drawbacks and applications. Food Chem. 2019, 272, 494-506, https://doi.org/10.1016/j.foodchem.2018.07.205.

32. Asefnejad, A.; Khorasani, M.T.; Behnamghader, A.; Farsadzadeh, B.; Bonakdar, S. Manufacturing of biodegradable polyurethane scaffolds based on polycaprolactone using a phase separation method: physical properties and in vitro assay. Int J Nanomedicine 2011, 6, 2375-2384, https://doi.org/10.2147/IJN.S15586.

33. Scarfato, P.; Avallone, E.; Iannelli, P.; De Feo, V.; Acierno, D. Synthesis and characterization of polyurea microcapsules containing essential oils with antigerminative activity. J. Appl. Polym. Sci. 2007, 105, 35683577, https://doi.org/10.1002/app.26420.

34. Moghbeli, M.; Abedi, V.; Dekamin, M., Microencapsulation of Ethion by Interfacial Polymerization Utilizing Potassium Phthalimide-N-oxyl (PPINO) as a Promoter. Iranian Journal of Chemical Engineering(IJChE) 2011, 8, 34-42.

35. Jayprakash, R.; Chandrani, A.N.; Powar, A.; S. handra. Design and application of polyurea microcapsules containing herbicide (oxyfluorfen). Designed Monomers and Polymers 2020, 23:1, 155-163, https://doi.org/10.1080/15685551.2020.1816344.

36. Chopde, S.; Datir, R.; Deshmukh, G.; Dhotre, A.; Patil, M. Nanoparticle formation by nanospray drying \& its application in nanoencapsulation of food bioactive ingredients. Journal of Agriculture and Food Research 2020, 2, 100085, https://doi.org/10.1016/j.jafr.2020.100085.

37. Bougarrani, S.; Sharma, P. K.; Hamilton, J. W. J.; Singh, A.; Canle, M.; El Azzouzi, M. Enhanced photocatalytic degradation of the imidazolinone herbicide imazapyr upon UV/Vis irradiation in the presence of CaxMNoy-TiO2 hetero-nanostructures: Degradation pathways and reaction intermediates. Nanomaterials 2020, 10, Article number 896, https://doi.org/10.3390/nano10050896.

38. Gallé, T; Frelat, M.; Huck, V.; Bayerle, M.; Pittois, D., Braun, C. Quantitative use of passive sampling data to derive a complete seasonal sequence of flood event loads: A case study for maize herbicides in Luxembourg. Environ. Sci. Proc. Impact. 2020, 22, 294-304, https://doi.org/10.1039/c9em00487d.

39. Gao, S.; Jiang, J.; Li, X.; Liu, Y.; Zhao, L.; Fu, Y. Enhanced physicochemical properties and herbicidal activity of an environment-friendly clathrate formed by $\beta$-cyclodextrin and herbicide cyanazine. J. Mol. Liq. 2020, 305, Article number 112858, https://doi.org/10.1016/j.molliq.2020.112858.

40. Jing, X.; Cheng, X.; Zhao, W.; Wang, H.; Wang, X. Magnetic effervescence tablet-assisted switchable hydrophilicity solvent-based liquid phase microextraction of triazine herbicides in water samples. J. Mol. Liq. 2020, 306, Article number 112934, https://doi.org/10.1016/j.molliq.2020.112934. 
41. Papadopoulos, N.; Zalidis, G. The Use of Typha Latifolia L. in Constructed Wetland Microcosms for the Remediation of Herbicide Terbuthylazine. Environ. Process. 2019, 6, 985-1003, https://doi.org/10.1007/s40710-019-00398-3.

42. Suma, N.; Aruldhas, D.; Joe, I. H.; Anuf, A. R.; Arun Sasi, B. S. Spectroscopic, quantum chemical, QTAIM analysis, molecular dynamics simulation, docking studies and solvent effect of pyridin-2-yl oxyacetic acid herbicide and its derivatives. J. Mol. Struct. 2020, 1206, Article number 127677, https://doi.org/10.1016/j.molstruc.2019.127677.

43. Suma, N.; Aruldhas, D.; Joe, I. H.; Sasi, B. S. A.; Anuf, A. R.; Mol, G. P. S. Spectroscopic and molecular structure investigation of Propachlor herbicide: A combined experimental and theoretical study. J. Mol. Struct. 2020, 1221, Artlce number 128866, https://doi.org/10.1016/j.molstruc.2020.128866.

44. Teutli-Sequeira, A.; Vasquez-Medrano, R.; Prato-Garcia, D.; Ibanez, J. G. Solar photo-assisted degradation of bipyridinium herbicides at circumneutral $\mathrm{pH}$ : A life cycle assessment approach. Processes 2020, 8 , Article number 1117, https://doi.org/10.3390/pr8091117.

45. Zhu, X.; Li, J.; Xie, B.; Feng, D.; Li, Y. Accelerating effects of biochar for pyrite-catalyzed Fenton-like oxidation of herbicide 2,4-D. Chem. Eng. J. 2020, 391, Article number 123605, https://doi.org/10.1016/j.cej.2019.123605. 